\title{
Wnt Signaling Inhibitor SM04755
}

National Cancer Institute

\section{Source}

National Cancer Institute. Wnt Signaling Inhibitor SM04755. NCI Thesaurus. Code C122693.

An orally bioavailable small molecule inhibitor of the Wnt signaling pathway, with potential antineoplastic activity. Upon oral administration, Wnt signaling inhibitor SM04755 targets and binds to an as of yet undisclosed target in the Wnt signaling pathway, thereby preventing Wnt-mediated signaling. This may inhibit growth of tumor cells in which the Wnt signaling pathway is overactivated. The Wnt signaling pathway is upregulated in many cancers and plays a key role in tumor cell proliferation. 